\title{
Epidemiological and Clinical Features of Hepatitis B Virus Genotypes among Immigrants in Southern Italy
}

\author{
Gaetano Scotto, ${ }^{1}$ Domenico Martinelli, ${ }^{2}$ Rocco Di Tullio, ${ }^{1}$ and Vincenzina Fazio ${ }^{3}$ \\ ${ }^{1}$ Clinica di Malattie Infettive, Università degli Studi di Foggia, Foggia 71100, Italy \\ ${ }^{2}$ Sezione di Igiene, Dipartimento di Scienze Mediche ed Occupazionali, Università di Foggia, Foggia 71100, Italy \\ ${ }^{3}$ Dipartimento di Laboratorio, Ospedali Riuniti, Foggia 71100, Italy
}

Correspondence should be addressed to Gaetano Scotto, gaescot@gmail.com

Received 5 August 2009; Revised 29 January 2010; Accepted 9 March 2010

Academic Editor: Hubert Erich Blum

Copyright () 2010 Gaetano Scotto et al. This is an open access article distributed under the Creative Commons Attribution License, which permits unrestricted use, distribution, and reproduction in any medium, provided the original work is properly cited.

\begin{abstract}
Background/aims. This study aims to determine the distribution and clinical features of HBV-genotypes in a population of immigrants affected by HBV-infection. Methods. Between 01/2003 and 03/2009, 1623 immigrants were tested for HBV-infection. Biochemical and virological activities were determined in HBsAg-positive patients; HBV-genotypes were determined, by the INNO-LiPA HBV Genotyping, in the subjects with HBV DNA detectable. In every patient we evaluated the stage and classified the infection as inactive carrier, mild or moderate/severe chronic hepatitis, cirrhosis, and/or HCC. Results. Among the tested subjects, 191 (11.7\%) resulted HBsAg-positive, and in 144/191 (75.4\%) serum HBV-DNA was detectable. The genotype distribution was as follows: $45,13 \%$ genotype E, 18,1\% genotype D, 15,3\% genotype B, 13,2\% genotype C, 4,9\% genotype A, 3,5\% mixed genotypes (A-D). The evaluation of liver disease degree showed that $24.6 \%$ patients were inactive carriers of HBV infection, $19.4 \%$ presented a immunotolerance phase, $34.5 \%$ had mild chronic hepatitis, $13.6 \%$ had a moderate/severe chronic hepatitis, $6.3 \%$ had cirrhosis, and $1.6 \%$ presented HCC. Conclusions. Our study evidences a high prevalence of HBV-infection in immigrants, and the potentiality of migratory flow in the introduction of genotype non-D hepatitis B virus. The Hepatitis B virus genotypes presented significant differences in epidemiological and clinical characteristics.
\end{abstract}

\section{Introduction}

Hepatitis B virus (HBV) infection is a global health problem, approximately 2 billion people in the world have been infected by HBV, and more than 350 million are chronic carriers of the virus. This infection is present mainly in some countries as Middle-East and South-East Asia, sub-Saharan Africa, Central and South-America, and East-Europe with a prevalence $>8 \%$ of population [1]. In the last twenty years a migratory flow has been going on from these countries to the industrialized countries (USA and West-Europe) with an increase of some infectious diseases (HIV, TB, viral hepatitis) $[2,3]$.

The migratory flow towards Italy has considerably increased in the last 10 years: at present the total number of legal immigrants can be estimated as 3.700 .000 subjects (6.2\% of all population) [4]. When considering these figures, it is obvious that, apart from questions regarding human rights, social-economic, and cultural integration, the range of health problems in immigrants is inevitably broad and includes, mainly, infectious diseases.

In our precedent study, the acute or chronic viral hepatitis represented the third cause of hospitalization for infectious diseases in immigrants (12\% of cases) after HIV infection (16\%) and tuberculosis (13\%). The viral hepatitis is most frequently related to HBV, particularly in African people coming from sub-Saharan areas, and South-East, or Far-East Asians [5].

But HBV infection is not always the same that we have been knowing for years in Italy, it is often a new infection with virological and clinical characteristics, HBV-genotypes related.

The HBV genome is a partially double-stranded circular DNA molecule consisting of 3200 nucleotides and exhibits considerable genetic variability; based on a nucleotide divergence $>8 \%$ in the entire viral genome, HBV has been 
established and classified into eight genotypes (A to $\mathrm{H}$ ) with a characteristic geographic distribution. Genotype A is widely distributed in North-West Europe, North-America and Central Africa, while genotype B and C are present in Asia only; genotype D has been found worldwide with its highest prevalence in the Mediterranean area, the Middle East, and South-Asia, particularly in India; genotype E is found in Sub-Saharan Africa and genotype F in South and Central America; genotype $G$ has been found in France and in the USA, while the newly discovered genotype $\mathrm{H}$ seems so far to be restricted to the northern part of Latin America, including Central America and Mexico $[6,7]$.

The accumulated evidences suggest that HBV genotypes have an impact on the natural course of chronic HBV infection with differences in the severity of underlying liver disease or treatment response [8-10].

In Italy, about $95 \%$ of Italian patients with $\mathrm{HBV}$ infection presents the genotype D [6]. Since the migratory flow towards our country is coming from endemic areas for HBV (prevalence $>8 \%$ ) such as East-Europe, sub-Saharan Africa and East Asia, the introduction in Italy of nonD HBV genotypes infection could be a natural consequence. This may be important both from the epidemiological and clinical point of view. In immigrants who live in different districts of Southern Italy the genotype distribution is strictly related to the typology of immigration and reflects the distribution for the areas of origin. In Campania and Lucania immigrants are coming mainly from Middle East Asia and North Africa; in Sicilia and Calabria from Middle East Asia, North Africa and from Central Africa; in Puglia the immigration is mainly from East Europe and from sub-Saharan Africa. In our geographical area (Foggia) there are mainly immigrants coming from Sub-Saharan Africa, East Europe and FarEast Asia. The aim of the present study is to determine, in a population of recent ( $<6$ months) immigrants the geographic distribution and virological characteristics of HBV genotypes and the association between different HBV genotypes and the clinical status of patients.

\section{Materials and Methods}

Between January 2003 and March 2009 a total of 1623 volunteer immigrants (about $45 \%$ of total population) were tested for infectious screening (HIV-HCV-TPHA-TB and $\mathrm{HBsAg}-\mathrm{HBsAb}-\mathrm{HBcAb}$ of $\mathrm{HBV}$ ) after obtaining appropriate informed consent. All tested subjects were temporarily guests in a refugee camp managed by the Italian Red Cross, located in Borgo Mezzanone (province of Foggia, Italy).

The study was reviewed and approved by the local Chief of the Red Cross and written informed consent was obtained from each study subject who was enrolled in the study. All study procedures were in agreement with the Helsinki Declaration (Edinburgh 2000). At enrolment, all study participants were interviewed using a questionnaire to obtain baseline demographic, clinical, and socioeconomic information and to assess their previous exposure to $\mathrm{HBV}$ Infection. All enrolled subjects also received a full clinical examination and were treated accordingly.
The average length of staying in Italy was 2 months (range 13-57 days) and the majority (1286, 79.3\%) came from Africa (41\% Eritrea, 35\% Somalia, 7.7\% Liberia); 239 subjects $(14.7 \%)$ came from Asia (8.8\% Pakistan, 3.2\% China, $0.5 \%$ Iraq), while 98 subjects $(6.0 \%)$ came from EastEurope (3.8\% Romania, 2.2\% Albania).

The mean age of the tested subjects was 27.3 years (range 1-56) and most of them were men $(83.7 \%)$. We evaluated, in HBsAg positive individuals, the biochemical and virological activity of infection and the eventual presence of coinfections (HCV, HDV, HIV); the HBVgenotype was determined in those with detectable serum HBV-DNA. HBsAg was assayed by commercial immunoassay (AbbottAuszyme Mc, Abbott Laboratories, North Chicago, IL, USA). Hepatitis B E Antigen (HbeAg) and antibody to $\mathrm{HBeAg}$ (anti-HBe) were detected by radioimmunoassay (HBeAg/antiHBe immunoradiometric DiaSorin, Vercelli, Italy). IgM and IgG anti-HDV were tested with commercially available ELISA kits (Abbott Diagnostics, WeisbadenDelkenheim, Germany). The presence of antibodies to $\mathrm{HCV}$ (anti-HCV) was determined by the use of a thirdgeneration enzyme-linked-immunoabsorbent assay (HCVELISA, Ortho Diagnostic System, Raritan, NJ, USA) and confirmed by a third-generation-recombinant-immunoblot assay (RIBA, Ortho Diagnostic Systems, Raritan, NJ, USA). Antibodies to HIV (anti-HIV) were determined by EIA (HIV1/HIV2, Abbott) and positive results were confirmed by Western Blot. Serum HBV-DNA levels were measured by a commercial PCR-real time with a detection limit of 100 copies/mL. Serum ALT was quantified by ultravioletenzymatic-assay (normal range 0-40 IU/L). For the determination of HBV genotypes, HBV-DNA was extracted as described by Stuyver et al. [11]. The extracted DNA was amplified over two rounds of PCR using biotinylated PCR primers. After the two PCR for amplification, HBVgenotypes were determined by the INNO-LiPA HBV Genotyping (Innogenetics NV, Gent, Belgium). The correct HBV genotype was determined by consulting an interpretation chart showing probe reactivity patterns for each $\mathrm{HBV}$ genotype.

\section{Evaluation of Liver Disease Degree}

All the patients with biochemical and/or virological activity of $\mathrm{HBV}$ infection refused to undergo liver biopsy. Therefore, for the evaluation and classification of liver disease degree we considered several parameters: bilirubine, AST/ALT (ratio $>1$ or $<1$ in nonalcoholic patients), viral load $\left(<10^{5}\right.$ or $>10^{5}$ copies $\left./ \mathrm{mL}\right)$, count of platelets $\left(>10^{5} / \mathrm{mm}^{3}\right.$ or $\left.<10^{5} / \mathrm{mm}^{3}\right)$, plasma proteins (hypoalbuminaemia, increased gammaglobulins), apolipoproteine $A_{1}$, aptoglobine, $\alpha 2$-macroglobuline, cholesterol, prothrombine time, gamma-glutammil-transferase, pseudocholinesterasis, abdominal echography. The disease degree was based on the analysis of more variable parameters; only for hepatocellular carcinoma (HCC) the main examen was the abdominal echography, followed, after the first diagnosis, by alphaphetoprotein and abdominal TC. 
The different degrees of chronic hepatitis B can be schematically divided into the following.

(1) "Immunotolerance phase" is characterized by HBeAg positivity (wild type infection), high levels of HBV replication (reflected by high levels of serum HBV DNA), normal or low levels of aminotransferase, mild or no liver necroinflammation and no or slow progression of fibrosis.

(2) Inactive HBV carrier state may follow seroconversion from $\mathrm{HBeAg}$ to anti-HBe antibodies. It is characterized by very low or undetectable serum HBV DNA levels and normal aminotransferase.

(3) Mild hepatitis: is marked by expansion of the portal zone by mononuclear cells and some fibrosis. The limiting plate of liver cells between portal zones and liver cell column is intact. Piecemeal necrosis of liver cells is not seen.

(4) Moderate hepatitis is marked by the presence of an inflammatory infiltrate, primarily of llymphocytes and plasma cells, which greatly expands the portal areas. The inflammatory infiltrate extends into the liver lobule, causing erosion of the limiting plate and piecemeal necrosis.

(5) Severe hepatitisis marked by fibrous septa extending into the liver columns with isolation of groups of liver cells in the form of rosettes. Intrahepatic "bridging", either portal-central or portal-portal, is seen.

\section{Statistical Analysis Methods}

To analyze the associations between genotypes (A, B, C, D, $\mathrm{E}$, and A-D mixed) and countries of origins, transaminases levels (AST and ALT $>40 \mathrm{UI} / \mathrm{mL}$ ), and stage of disease (immunotollerance, mild hepatitis, moderate/severe hepatitis, cirrhosis, hepatocellular carcinoma), $2 \times 2$ contingence tables were constructed and chi square $\left(\chi^{2}\right)$ or Fisher test was calculated. When it was possible, OR and its relative $95 \%$ CI was calculated. To compare the levels of viremia among different genotypes, Kruskal-Wallis test was performed. The chosen level of statistical significance was $P<.05$. Statistical calculations were performed using STATA 10 MP for Mac Os.

\section{Results}

Among the 1623 tested subjects, 191 (11.7\%) resulted HBsAg positive, 146 males and 45 females. The mean age of positive subjects was 26 years (range 19-47); 96 patients (50.2\%) came from Africa (30 from Liberia, 42 from Eritrea, and 24 from Somalia), 59 (31.0\%) from Asia (38 from China and 21 from Pakistan) and 36 (18.8\%) from East-Europe (19 from Romania and 17 from Albania). One hundred and forty-eight patients were anti-HBe positive while 43 presented HBV wild (HBsAg-HBeAg positive) type. No subject presented coinfection with HIV. Sixteen patients showed coinfection with HDV, nine with $\mathrm{HCV}$ and three with HCV-HDV. All the subjects with coinfection did not present $\mathrm{HCV}$ and/or HDV viral replication.
Forty seven/191 (24.6\%) patients presented normal ALT levels $(<40 \mathrm{IU} / \mathrm{L})$ and undetectable serum HBV DNA $(<100$ copies $/ \mathrm{mL})$, thirty-seven $(19.4 \%)$ subjects presented persistent normal ALT levels, but HBV-DNA detectable by PCR Real Time (mean level 1374231 copies/mL, range 74651-13.875.247), while 107 (56.0\%) patients had elevated ALT levels (mean level $141 \mathrm{IU} / \mathrm{L}$, range 68-297) and serum HBV-DNA detectable (mean level 1561183 copies/mL, range 22.933-11.290.865).

Genotype distribution, among all the HBV DNA positive patients, was determined as follows: 65 genotype E (45.13\%), 26 genotype $\mathrm{D}(18.1 \%), 22$ genotype $\mathrm{B}(15.3 \%), 19$ genotype C (13.2\%), 7 genotype A (4.9\%), and 5 mixed genotypes (A-D) $(3.5 \%)$. Genotype E was associated to Eritrean (OR: 26.1, 95\% CI: $\left.7.2-139.2 ; \chi^{2}=41.96, P<.001\right)$ and Liberian subgroups (OR and 95\% CI not calculable; $\chi^{2}=31.56$, $P<.001)$. Genotype A was associated to Somali subgroup (OR: 16.9, 95\% CI: 2.4-126.5; $\chi^{2}=18.85, P<.001$ ). Genotypes $\mathrm{C}$ and $\mathrm{B}$ were associated to Chinese subgroup (resp., OR: 39.1, 95\% CI: 9.3-223.4; $\chi^{2}=50.9, P<.001$ (OR: 14.1, 95\% CI: 4.5-46.7; $\chi^{2}=33.46, P<.001$ ). Genotype D was associated to Pakistani (OR: 15.4, 95\% CI: $\left.5.2-47.6 ; \chi^{2}=38.53, P<.001\right)$ and to Albania subgroups (OR and 95\% CI: not calculable; $\chi^{2}=38.44$, $P<.001)$. Also genotypes A-D mixed was associated to Pakistani subgroup (OR and 95\% CI: not calculable; $\chi^{2}=$ 17.42, $P<.001)$.

HBV wild type infection was present in $15 / 19$ patients with genotype C (78.9\%), in 14/22 patients with genotype B $(63.6 \%)$, in $12 / 65$ patients with genotype $\mathrm{E}(18.5 \%)$, and in $2 / 26$ patients with genotype $\mathrm{D}(7.7 \%)$.

The mean ALT, in the patients with altered serum level, was similar among the five different genotypes (143 \pm $37 \mathrm{UI} / \mathrm{mL}$.), without any association between any genotypes and AST and ALT $>40 \mathrm{UI} / \mathrm{mL}(P>.05)$, respectively. The level of HBV replication differed between HBV genotypes, with a mean rate of $1.5 \times 10^{6}$ copies $/ \mathrm{mL}$ (range $2.2 \times 10^{4}-1.1 \times$ $10^{7}$ ), with the highest values for genotype $\mathrm{C}$ and the lowest meanvalues for genotype $\mathrm{E}\left(8.7 \times 10^{5}\right.$ copies $\left./ \mathrm{mL}\right)$. There was a significant difference in levels of viremia among different genotypes $\left(\chi^{2}=54.47, P<.001\right)($ Table 1$)$.

The evaluation of liver disease degree showed that $47 / 191$ (24.6\%) patients were inactive carriers of HBV infection, 37 presented a phase of immunotolerance, $66(34.5 \%)$ had mild chronic hepatitis, $26(13.6 \%)$ had a moderate/severe chronic hepatitis, $12 / 191(6.3 \%)$ had cirrhosis and $3(1.6 \%)$ presented HCC. In Table 2 is shown the HBV infection degree according to HBV genotypes.

There was not association between any genotypes and immunotollerance state $(P>.05)$. Genotype $\mathrm{E}$ was associated with "mild chronic hepatitis" (OR: 4.2, 95\% CI: 2-8.9; $\left.\chi^{2}=16.84, P<.001\right)$. There was not association between any genotypes and "moderate/severe hepatitis or cirrhosis" $(P>$ $.05)$. Genotypes A-D mixed was associated to "hepatocellular carcinoma" (OR: 92, 95\% CI: 3.2-5455.3; $P<.05$ ).

Looking at the thirty-eight patients with moderate/severe hepatitis or cirrhosis, in 20 of them $(52.6 \%)$ the disease was related to HBV wild infection, while $18(47.4 \%)$ were antiHBe positive $(P>.05)$. 
TABLE 1: Distribution of HBV genotypes according to country of origin, mean of transaminase $(P>.05)$, and mean of viremia $(P<.001)$.

\begin{tabular}{|c|c|c|c|c|}
\hline Genotypes & Patients & Country of origin & $\begin{array}{c}\text { Mean AST/ALT } \\
\text { levels }(\mathrm{nv}<40 \mathrm{UI} / \mathrm{L})\end{array}$ & $\begin{array}{c}\text { Mean HBV-DNA } \\
(\mathrm{nv}<20 \text { copies } / \mathrm{mL})\end{array}$ \\
\hline \multirow{3}{*}{$\mathrm{E}$} & \multirow{3}{*}{$65(45,13 \%)$} & 33 Eritrea & \multirow{3}{*}{$124 / 150$} & \multirow{3}{*}{871.900} \\
\hline & & 22 Liberia & & \\
\hline & & 10 Somalia & & \\
\hline \multirow{3}{*}{$\mathrm{D}$} & \multirow{3}{*}{$26(18,1 \%)$} & 10 Romania & \multirow{3}{*}{$131 / 137$} & \multirow{3}{*}{1.278 .831} \\
\hline & & 8 Albania & & \\
\hline & & 8 Pakistan & & \\
\hline \multirow{2}{*}{ B } & \multirow{2}{*}{$22(15,3 \%)$} & 15 China & \multirow{2}{*}{$132 / 143$} & \multirow{2}{*}{1.176 .900} \\
\hline & & 7 Pakistan & & \\
\hline \multirow{2}{*}{$\mathrm{C}$} & \multirow{2}{*}{$19(13,2 \%)$} & 16 China & \multirow{2}{*}{$118 / 154$} & \multirow{2}{*}{2.961 .000} \\
\hline & & 3 Pakistan & & \\
\hline \multirow{2}{*}{ A } & \multirow{2}{*}{$7(4,9 \%)$} & 4 Somalia & \multirow{2}{*}{$112 / 128$} & \multirow{2}{*}{1.343 .272} \\
\hline & & 3 Eritrea & & \\
\hline MIxed (A/D) & $5(3,5 \%)$ & 5 Romania & $127 / 135$ & 1.735 .200 \\
\hline
\end{tabular}

TABLE 2: HBV infection degree according to genotype, see the text.

\begin{tabular}{|c|c|c|c|c|c|c|}
\hline & \multicolumn{6}{|c|}{ Genotypes } \\
\hline & $\mathrm{E}$ & $\mathrm{D}$ & $\mathrm{B}$ & $\mathrm{C}$ & A & Mixed \\
\hline Immunotolerance $P>.05$ & 16 & 7 & 9 & 3 & 2 & 0 \\
\hline Mild chronic hepatitis & $\begin{array}{c}42 \\
P<.001\end{array}$ & 9 & 7 & 6 & 2 & 0 \\
\hline Moderate/severe chron. hepatitis $P>.05$ & 7 & 6 & 4 & 5 & 2 & 2 \\
\hline Cirrhosis $P>.05$ & 0 & 4 & 2 & 4 & 1 & 1 \\
\hline Hepatocarcinoma & & & & & & 2 \\
\hline Mixed $P<.05$ & 0 & 0 & 0 & 1 & 0 & \\
\hline
\end{tabular}

\section{Discussion}

Some recent studies have shown how in immigrants $\mathrm{HBV}$ infection represents one of the prevalent infectious diseases, particularly in African people coming from sub-Saharan areas $[5,7,12,13]$, with a rate of infection $>8 \%$, higher than in Western Countries, probably caused by the lack or incomplete prophylactic vaccination in the country of origin and with risky sexual behaviour.

In our study we evaluated the prevalence, the typology of HBV-infection and the degree of disease, according to genotypes, in a population of immigrants to Italy, by a mean period of 2 months. This is the first study in Italy which evaluates the stage of HBV chronic hepatitis according to its viral genotype; previous studies had only showed the heterogeneity of the virus according to the subjects' geographical area $[14,15]$. The results (HBsAg positive rate of $11.7 \%$ ) reflect the actual prevalent migratory flow to Italy, especially in our geographic area, mostly represented by people coming from Africa [4]. An important finding was that almost all HBsAg-positive subjects were men, but this data could be related to the difficulty in testing females (only 349/1623 of tested subjects were females). In fact, in African communities females fear to know their eventual diseases, particularly infectious diseases which are considered a further cause of social discrimination [5].
The vast majority of cases were infected by genotype $\mathrm{E}$ and this coincides with the usual geographic distribution of this genotype, which is exclusively diffused in subSaharan areas [13]. Other HBV genotypes were also found among immigrants to our country, like D-B-C-A and mixed genotypes, thus reflecting different areas of origin [11, 16, 17]. This redistribution of HBV genotypes represent an important change in the epidemiology of infection, increasing the number of infected subjects in our country, with a "different" hepatitis, also if the risk of contamination with a "new virus" for Italian population is low, because the HBV vaccination defends from a reinfection.

Recently, there have been several studies reporting the influence of HBV genotypes on the clinical features $[8,9,18]$ and on the response to antiviral treatment (interferon and lamivudine) of patients infected with $\operatorname{HBV}[10,19,20]$. Therefore the different genotypes, probably characterized by a different natural history and a different response to therapy, could require a different clinical and therapeutic approach compared to genotype-D. In order to further investigate these associations, we have examined in our patients the influence of HBV genotypes on the liver disease progression. All the patients refused to undergo liver biopsy, therefore for the evaluation and classification of liver disease degree we considered the noninvasive markers of fibrosis and inflammation in clinical practice, mainly the Fibrotest/Apritest, 
because the data of literature showed that these markers are a reliable method for predicting significant liver fibrosis and necroinflammation in both viral and nonviral chronic liver disease patients.

Several tested subjects (about 25\%) were inactive HBV carriers. A normal ALT level finding is not surprising, since $\mathrm{HBV}$-infection has an high prevalence $(>8 \%)$ in sub-Saharan people, but many infected subjects (a variable rate of $40 \%-$ $65 \%$ in different studies) do not show disease's biochemical activity [13].

The prevalence of immunotolerance phase and mild chronic hepatitis was mainly observed in patients with genotype E. This is absolutely usual given the origin of the patients and the fact that at least part of them (and probably not a small one) is supposed to have acquired HBV vertically and thus might have developed immunotolerance to the virus. These ones were all from Sub-Saharan Africa, where HBV transmission mostly occurs during early childhood, and were characterized by both a younger age and a lower viral load than the other genotypes. Despite high endemicity, little was known about HBV genotype distribution across Africa until recently, when genotype $\mathrm{E}$ was found to be characterized by a high prevalence and vast geographical distribution (about one-third) in the African continent [21].

In a study among blood donors in Ghana, all infected by genotype E, the mean viral load was relatively low even in 16-19-years-old patients. Therefore the highest rate of mild disease in genotype E, observed in our study, may be related overall to younger age of infection and lower HBVDNA levels [22].

In conclusion, our study evidences a high prevalence of $\mathrm{HBV}$-infection in immigrants. The global migratory flow to our country, mainly from tropical areas, can determine a partial modification of the normal geographic distribution of HBV-genotypes, with the introduction of nonD genotypes, potentially characterized by different natural history and response to antiviral regimens.

\section{Acknowledgment}

This study has been presented and accepted as poster at EASL Copenhagen 2009, Abstract no. 357.

\section{References}

[1] D. Lavanchy, "Hepatitis B virus epidemiology, disease burden, treatment, arid current and emerging prevention and control measures," Journal of Viral Hepatitis, vol. 11, no. 2, pp. 97-107, 2004.

[2] R. López-Vélez, H. Huerga, and M. C. Turrientes, "Infectious diseases in immigrants from the perspective of a tropical medicine referral unit," The American Journal of Tropical Medicine and Hygiene, vol. 69, no. 1, pp. 115-121, 2003.

[3] R. Paterson, "Screening immigrants for infectious diseases," The Lancet Infectious Diseases, vol. 3, no. 11, p. 681, 2003.

[4] Caritas Italiana/Migrantes, "La popolazione e lo sviluppo nel mondo di oggi; I flussi di ingresso nel 2006," in Immigrazione Dossier Statistico XVII Rapporto, pp. 15-25, 67-75, IDOS, Rome, Italy, 2007.
[5] G. Scotto, A. Saracino, R. Pempinello, et al., "Gruppo Italiano per lo Studio delle Malattie Infettive negli Immigranti: epidemiological multicentric study on prevalence of hepatitis in hospitalised immigrants Italy during 2002," Annali di Igiene, vol. 17, no. 1, pp. 11-18, 2005.

[6] Y. Miyakawa and M. Mizokami, "Classifying hepatitis B virus genotypes," Intervirology, vol. 46, no. 6, pp. 329-338, 2003.

[7] J. M. Echevarrìa, A. Avellòn, and L. O. Magnius, "Molecular epidemiology of hepatitis B virus in Spain: identification of viral genotypes and prediction of antigenic subtypes by limited sequencing," Journal of Medical Virology, vol. 76, no. 2, pp. 176-184, 2005.

[8] H. Sumi, O. Yokosuka, N. Seki, et al., "Influence of hepatitis $\mathrm{B}$ virus genotypes on the progression of chronic type B liver disease," Hepatology, vol. 37, no. 1, pp. 19-26, 2003.

[9] H. L.-Y. Chan, S. W.-C. Tsang, C.-T. Liew, et al., "Viral genotype and hepatitis B virus DNA levels are correlated with histological liver damage in HBeAg-negative chronic hepatitis B virus infection," American Journal of Gastroenterology, vol. 97, no. 2, pp. 406-412, 2002.

[10] C.-J. Liu, J.-H. Kao, and D.-S. Chen, "Therapeutic implications of hepatitis B virus genotypes," Liver International, vol. 25, no. 6, pp. 1097-1107, 2005.

[11] L. Stuyver, S. De Gendt, C. Van Geyt, et al., "A new genotype of hepatitis B virus: complete genome and phylogenetic relatedness," Journal of General Virology, vol. 81, no. 1, pp. 6774, 2000.

[12] J. M. Ramos, C. Pastor, M. F. M. Masia, E. Cascales, G. Royo, and F. Gutierrez-Rodero, "Health in the immigrant population: prevalence of latent tuberculosis, hepatitis B, hepatitis C, human immunodeficiency virus and syphilis infection," Enfermedades Infecciosas y Microbiologia Clinica, vol. 21, no. 10, pp. 540-542, 2003.

[13] D. Candotti, O. Opare-Sem, H. Rezvan, F. Sarkodie, and J.-P. Allain, "Molecular and serological characterization of hepatitis B virus in deferred Ghanaian blood donors with and without elevated alanine aminotransferase," Journal of Viral Hepatitis, vol. 13, no. 11, pp. 715-724, 2006.

[14] E. Palumbo, G. Scotto, G. Faleo, D. C. Cibelli, A. Saracino, and G. Angarano, "Prevalence of HBV-genotypes in immigrants affected by HBV-related chronic active hepatitis," Arquivos de Gastroenterologia, vol. 44, no. 1, pp. 54-57, 2007.

[15] E. Palumbo, G. Scotto, D. C. Cibelli, A. Saracino, and G. Angarano, "Immigration and hepatitis B: virus: epidemiologica, clinical and therapeutic aspects," Eastern Mediterranean Health Journal, vol. 14, no. 4, pp. 784-790, 2008.

[16] M.-F. Yuen, E. Sablon, Y. Tanaka, et al., "Epidemiological study of hepatitis B virus genotypes, core promoter and precore mutations of chronic hepatitis B infection in Hong Kong," Journal of Hepatology, vol. 41, no. 1, pp. 119-125, 2004.

[17] X. Ding, M. Mizokami, X. Ge, et al., "Different hepatitis B virus genotype distributions among asymptomatic carriers and patients with liver diseases in Nanning, southern China," Hepatology Research, vol. 22, no. 1, pp. 37-44, 2002.

[18] M.-F. Yuen, E. Sablon, H. -J. Yuan, et al., "Significance of hepatitis B genotype in acute exacerbation, HBeAg seroconversion, cirrhosis-related complications, and hepatocellular carcinoma," Hepatology, vol. 37, no. 3, pp. 562-567, 2003.

[19] K. Jia-Horng, W. Nan-Hu, C. Pei-Jer, L. Ming-Yang, and C. Ding-Shinn, "Hepatitis B genotypes and the response to interferon therapy," Hepatology, vol. 33, pp. 998-1002, 2000. 
[20] C. A. Valdes, M. Buti, R. Jardi, et al., "The role of HBV genotype in the emergence of YMDD variants in chronic hepatitis B patients treated with lamivudine," Hepatology, vol. 38, supplement 2, p. 178, abstract no. 613.

[21] M. Buti, I. Elefsiniotis, R. Jardi, et al., "Viral genotype and baseline load predict the response to adefovir treatment in lamivudine-resistant chronic hepatitis B patients," Journal of Hepatology, vol. 47, no. 3, pp. 366-372, 2007.

[22] C. Bekondi, C. M. Olinger, N. Boua, et al., "Central African Republic is part of the West-African hepatitis B virus genotype E crescent," Journal of Clinical Virology, vol. 40, no. 1, pp. 3137, 2007. 


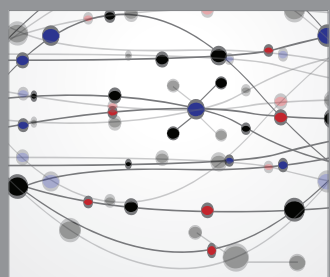

The Scientific World Journal
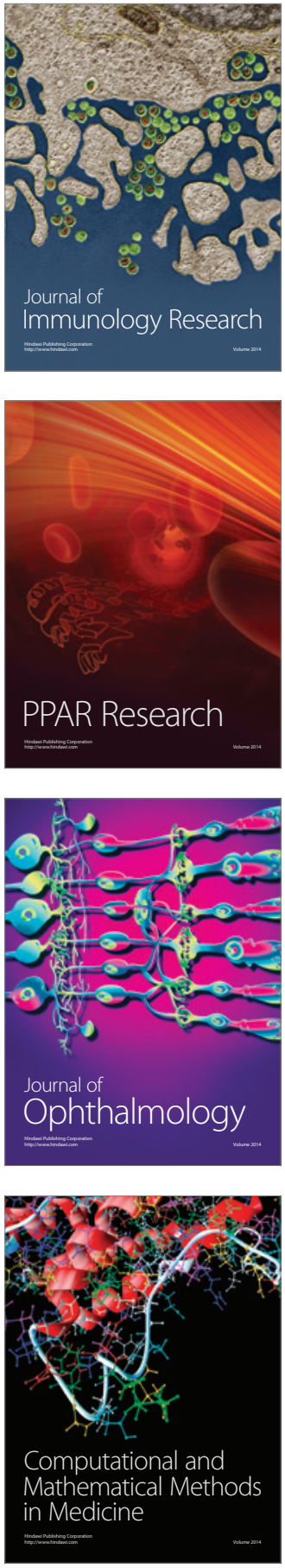

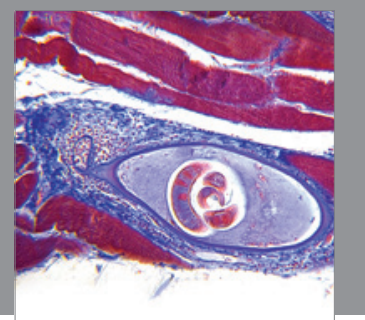

Gastroenterology

Research and Practice
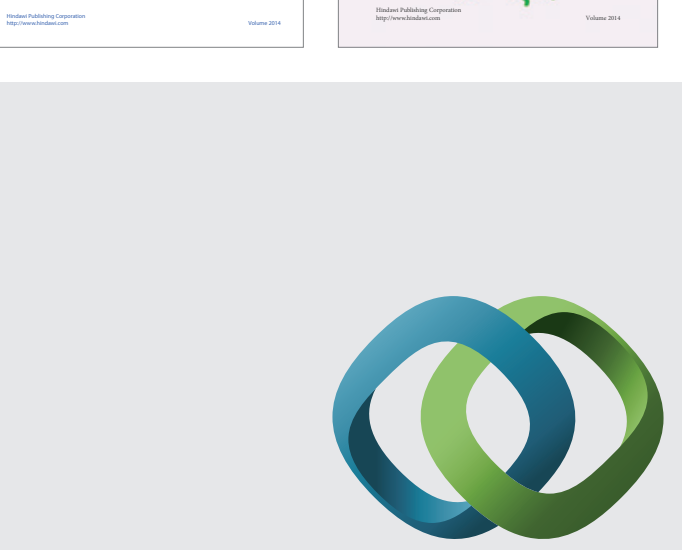

\section{Hindawi}

Submit your manuscripts at

http://www.hindawi.com
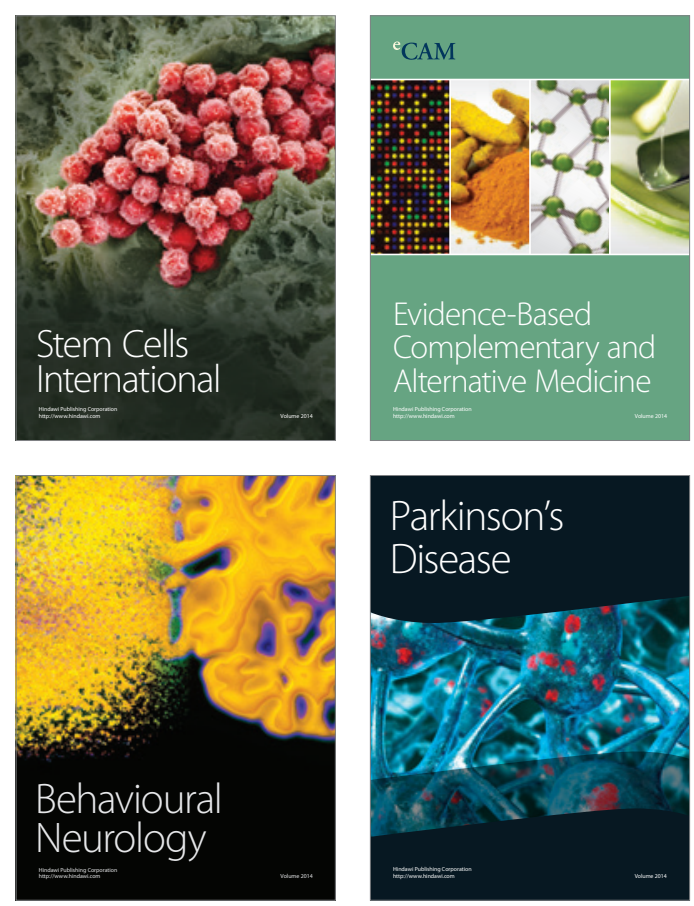

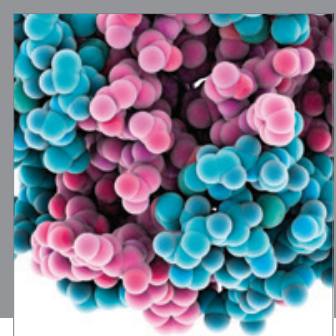

Journal of
Diabetes Research

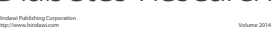

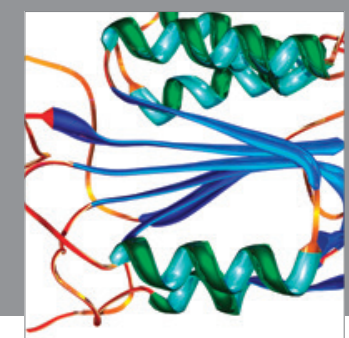

Disease Markers
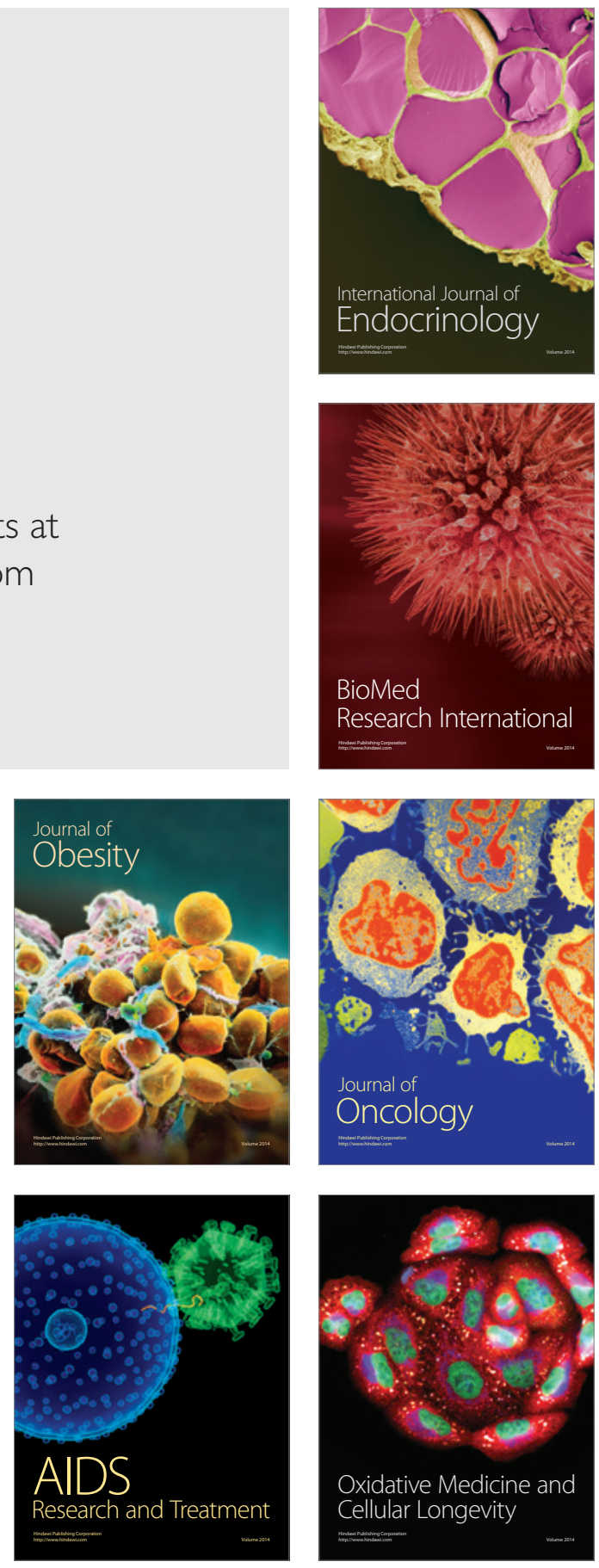